\title{
lliofemoral Vein Stenting in a Patient with Pelvic Metastasis
}

\author{
Sina Zarrintan ${ }^{1,2}$, Negin Yavari $^{3}$, Niki Tadayon ${ }^{2,4}$, Fuad Majidi ${ }^{4}$, Seyed Masoud Hosseini ${ }^{4}$, \\ Hamidreza Haghighatkhah ${ }^{5}$, Ehsan Parvas ${ }^{4}$, and Seyed Moahammad Reza Kalantar-Motamedi ${ }^{2,4}$ \\ ${ }^{1}$ Cardiovascular Research Center, Tabriz University of Medical Sciences, Tabriz, ${ }^{2}$ Phlebology Research Group, Shahid Beheshti \\ University of Medical Sciences, Tehran, ${ }^{3}$ Tehran Heart Center, Tehran University of Medical Sciences, Tehran, ${ }^{4}$ Division of Vascular \\ Et Endovascular Surgery, Department of General \& Vascular Surgery, ${ }^{5}$ Department of Radiology, Shohada-Tajrish Hospital, Shahid \\ Beheshti University of Medical Sciences, Tehran, Iran
}

\begin{abstract}
We report a case of an 81-year-old woman with extensive pelvic lymphadenopathy that caused severe stenosis and occlusion of the right common and external iliac veins and proximal common femoral vein. Pelvic lymphadenopathy resulted from the recurrence of a previous right ovarian epithelial tumor. The patient had severe right lower extremity edema, consistent with severe venous insufficiency. She was treated with high-pressure balloon angioplasty (12-14 $\mathrm{mm}$ in diameter) and four self-expanding stents (14-10 $\mathrm{mm}$ diameter, $80-40 \mathrm{~mm}$ length). The postoperative response was dramatic to a near-complete resolution of the edema. The venous clinical severity scores were 10 and 2 at presentation and 6 months after the follow-up, respectively. Balloon angioplasty and stenting are safe and effective methods for providing symptomatic relief for lower extremity venous insufficiency in patients with extensive and unresectable pelvic masses.
\end{abstract}

Key Words: Iliac vein, Self expandable metallic stents, Pelvic neoplasms, Angioplasty
Received December 9, 2020 Revised February 15, 2021

Accepted March 22, 2021

Published on June 30, 2021

Corresponding author: Niki Tadayon Division of Vascular \& Endovascular Surgery, Department of General \& Vascular Surgery, Shohada-Tajrish Hospital, Tajrish Square, Tehran 1989934148, Iran

Tel: 98-21-22721144

Fax: 98-21-22721144

E-mail: nntadayon@gmail.com https://orcid.org/0000-0001-9431-4411

Copyright (C) 2021 The Korean Society for Vascular Surgery

This is an Open Access article distributed under the terms of the Creative Commons Attribution Non-Commercial License (http://creativecommons.org/licenses/by-nc/4.0) which permits unrestricted non-commercial use, distribution, and reproduction in any medium, provided the original work is properly cited.

Vasc Specialist Int • https://doi.org/10.5758/vsi.200080

\section{INTRODUCTION}

Huge and unresectable pelvic masses could cause iliofemoral venous occlusion, primarily due to thrombosis and secondarily due to external compression of a mass, malignant invasion, fibrosis, or intraluminal extension of the tumor [1,2]. lliac vein compression and venous insufficiency result in pain, swelling, stasis ulcer, skin hyperpigmentation, varicosities, and venous claudication, which can compromise the quality of life [3,4]. Endovascular venoplasty and stent placement are minimally invasive techniques that are increasingly being considered as palliative therapy in addition to conventional therapies $[5,6]$.

We present a case of severe iliofemoral vein stenosis and occlusion resulting from extensive pelvic masses. The patient was treated successfully with iliac venous stenting with the reestablishment of venous blood flow. In addition, we provide a comprehensive review of previously reported cases. Informed consent has been obtained from the patient for this case report.

\section{CASE}

An 81-year-old woman with a history of the right ovarian epithelial tumor was referred to our vascular surgery center at Shohada-Tajrish Hospital, Shahid Beheshti University of Medical Sciences, Tehran, Iran, with right lower extremity swelling. The patient had undergone total abdominal hysterectomy and bilateral oophorectomy in 2012. She had received a full course of chemotherapy due to postoperative epithelial neoplasm. She did not have any follow-up visits for the past 7 years. The patient had severe right lower ex- 
tremity edema both in the calf and thigh and diffuse skin pigmentation at the ankle and calf. There was no inflammation or skin ulcer. The patient had severe lifestyle-limiting symptoms such as pain. In addition, a few scattered varicosities in the thigh were observed. Distal arterial pulses were normal. The patient was not compliant with compression therapy. We performed a complete cancer work-up using medical and surgical oncology services. Thoracic and abdominopelvic spiral computed tomography revealed an irregular mass in the right pelvic fossa, indicating extensive lymphadenopathy and recurrence of ovarian cancer. Moreover, liver metastases were observed (Fig. 1). Because of lifestyle-limiting lower extremity venous insufficiency and the patient not being a candidate for oncological surgery, we decided to investigate the right iliac venous involvement and re-establish venous drainage.

Venography was performed under close monitoring of vital signs, mild sedation, and local anesthesia. Diffuse severe stenosis and occlusion were observed in the common iliac vein (CIV), external iliac vein (EIV), and common femoral vein (CFV) in the anteroposterior (AP), lateral, right oblique, and left oblique projections (Fig. 2A). In addition, extensive collateral venous drainage was observed (Fig. 2B). The Seldinger technique was used to insert a sheath into the right superficial femoral vein $20 \mathrm{~cm}$ below the inguinal ligament under ultrasound guidance. The sheath was exchanged with a 9-Fr sheath, and subsequently, 12-mm and 14-mm high-pressure balloons were used to perform venoplasty in the right iliofemoral vein territory. Thereafter, four self-expanding stents were inserted. A 14-mm diameter, 80-mm length stent was inserted into the right CIV, followed by two $12 \times 40-\mathrm{mm}$ and one $10 \times 60-\mathrm{mm}$ stents into the distal right CIV, EIV, and right CFV, respectively. All stents were self-expanding (Venovo; Bard Peripheral Vascular Inc., Tempe, AZ, USA). Balloon inflation was repeated using 12-mm and 14-mm high-pressure balloons (Fig. 3A).
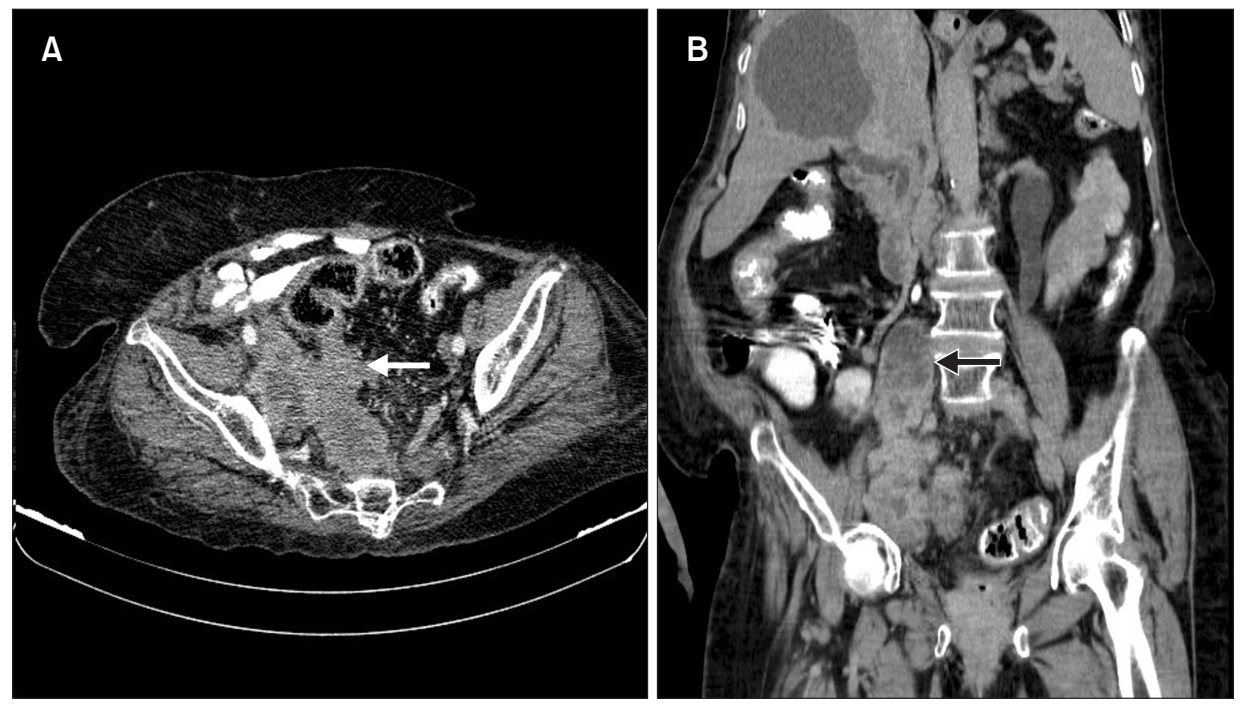

Fig. 1. Axial (A) and coronal (B) non-contrast computed tomography scans of abdomen and pelvis showed bulky and elongated huge right iliac lymphadenopathy (arrows) causing iliac vein compression and obstructing the intraperitoneal extension and rectosigmoid wall involvement. In addition, large hypodense round metastasis in the right liver lobe was evident.
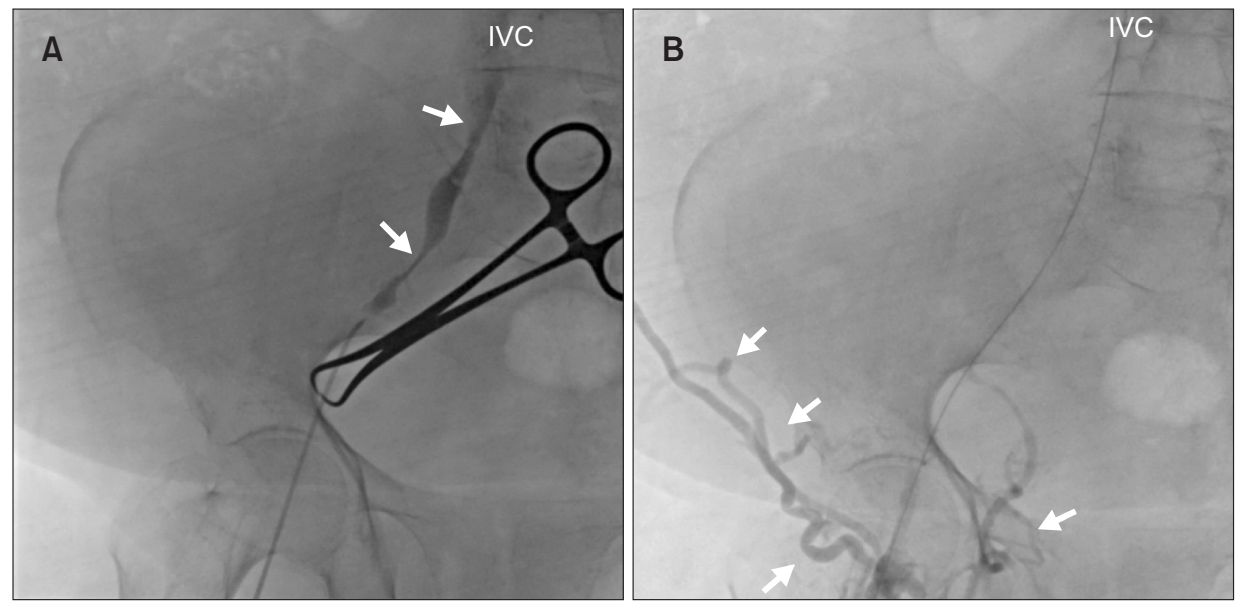

Fig. 2. (A) Occlusion and severe stenosis (arrows) in the territory of the iliofemoral vein secondary to the involvement by pelvic malignancy. (B) A guidewire was passed through the iliofemoral vein and located in the inferior vena cava (IVC). Collateral venous drainage of the right iliofemoral region is evident (arrows). 

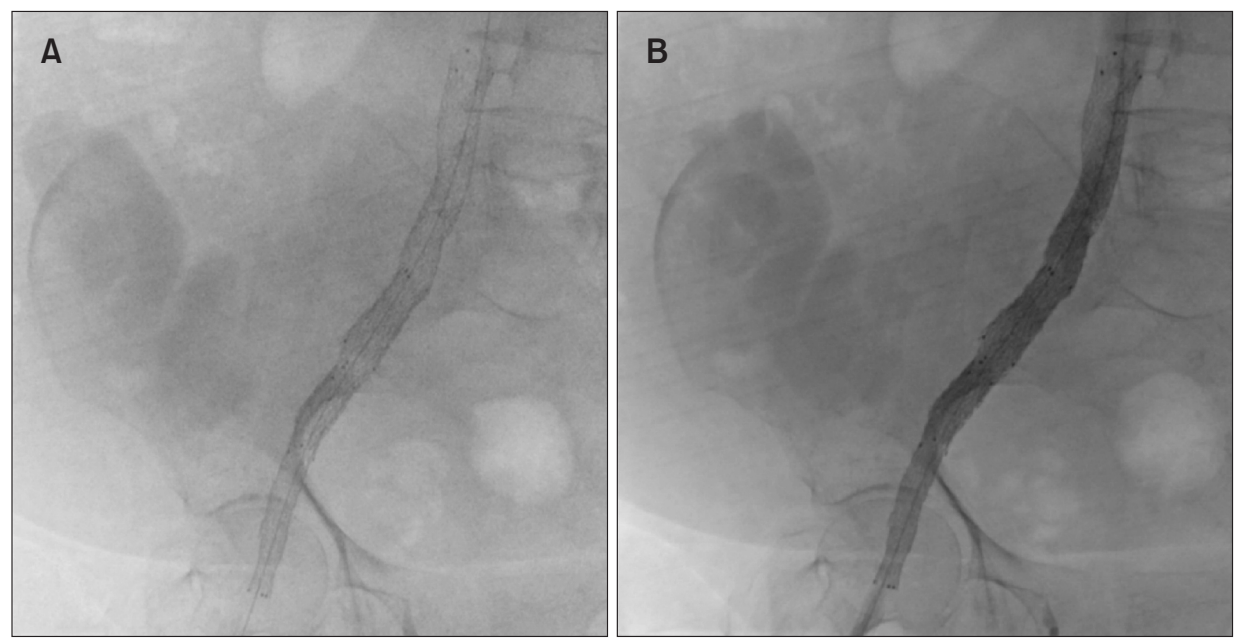

Fig. 3. (A) Self-expanding stents were inserted into the right iliofemoral veins. (B) Completion venography showed recanalized vein with disappeared collaterals.

The completion venography showed technical success, i.e., successful inflation of the angioplasty. The stents were inserted at precise anatomic locations. The venous drainage was intact, and the collateral veins had disappeared (Fig. $3 \mathrm{~B})$. The proximal stent was extended to the distal inferior vena cava (IVC), and the distal stent was extended to the proximal CFV, proximal to the femoral vein bifurcation. Because of the extrinsic compression and possible diffuse fibrosis due to pelvic malignancy, we used stents smaller than the standard size: $10 \mathrm{~mm}$ for CFV, $12 \mathrm{~mm}$ for EIV, and $14 \mathrm{~mm}$ for CIV.

After insertion of the sheath, 5,000 international units (IU) of heparin sulfate were administered intravenously. After stenting, $300 \mathrm{mg}$ clopidogrel was administered orally. The patient was administered a heparin drip (1,000 IU per hour) for 2 days after the procedure. The postoperative course of the patient was uneventful. The edema subsided considerably. The patient had moderate pain in the right lower extremity, particularly in the inguinal region. Warfarin $5 \mathrm{mg}$ daily and clopidogrel $75 \mathrm{mg}$ daily were administered. In addition, the patient was advised to use class 111 below-knee compression stockings during the day.

Three follow-up visits were performed every 2 months. The patient had mild to moderate pain in the right inguinal region during the first visit. She had a strange feeling of a metal object in her right inguinal region. At the second visit, the pain and strange sensation disappeared. The edema resolved near completely at the third follow-up, and the patient had ankle edema only in the evening. Clopidogrel was discontinued after 6 months and the patient was on warfarin. Duplex ultrasonography at follow-up visits revealed normal venous drainage with patent stents. The venous clinical severity scores were 10 and 2 at presentation and after the 6-month follow-up, respectively.

\section{DISCUSSION}

We report a case of iliac venous stenting in a patient with severe iliofemoral vein steno-occlusion due to recurrent ovarian cancer. Severe venous insufficiency was successfully resolved by endovascular stenting. Endovascular venous stenting could be a feasible technique for improving the symptoms of venous insufficiency due to unresectable pelvic malignancy.

Chronic venous obstruction can be extremely debilitating in patients with cancer [7]. Until the introduction of endovascular venous stenting, long-term anticoagulation, compression therapy, balloon angioplasty, and bypass surgery were used to treat the patients. However, these were associated with potential complications and limitations (1, 2). Invasive procedures, such as surgical bypass, in venous stenosis resulting from diffuse pelvic malignancies are limited, and the failure rate is relatively high $[8,9]$. There is no definite treatment for venous obstruction in patients with diffuse pelvic malignant tumors. Rapid resolution of symptoms after venoplasty and stenting of iliac veins indicates the effectiveness of endovascular therapy. However, endovascular stenting is associated with certain complications, such as recanalization failure, rupture, and restenosis. Nevertheless, alleviation of symptoms by endoluminal approaches is an effective strategy in patients with poor survival, such as those with unresectable malignant pelvic masses.

Table 1 illustrates the reported cases of iliofemoral venous obstruction due to malignancies. Malignant tumors can compress or invade the adjacent iliac veins, resulting in stenosis or occlusion. Types of malignancies, involved veins, and their management are summarized in Table 1 [1,2,5,6,8,10-13]. Different kinds of pelvic malignancies, including bladder, prostate, ovarian, cervical, endometrial, 
Table 1. Reported cases of malignancy-related iliofemoral venous obstruction

\begin{tabular}{|c|c|c|c|c|c|c|}
\hline Reference & $\begin{array}{l}\text { Case } \\
\text { no. }\end{array}$ & $\begin{array}{l}\text { Age } \\
\text { (y) }\end{array}$ & Etiologic cancer & Involved vein & Used stent $(\mathrm{mm})$ & Outcome \\
\hline $\begin{array}{l}\text { Tadayon et al. } \\
\text { [11], } 2021\end{array}$ & 1 & 66 & $\begin{array}{l}\text { Papillary urothelial } \\
\text { cancer of bladder }\end{array}$ & REIV & $\begin{array}{l}\text { SES, Venovo } \\
(12 \times 80)\end{array}$ & $\begin{array}{l}\text { Symptom relief, patent stent at } \\
6 \text { months. }\end{array}$ \\
\hline $\begin{array}{l}\text { Taslakian et al. } \\
\text { [12], } 2018\end{array}$ & 1 & 73 & $\begin{array}{l}\text { Bladder and prostate } \\
\text { cancer }\end{array}$ & $\begin{array}{l}\text { RCIV, REIV } \\
\text { and RCFV }\end{array}$ & $\begin{array}{l}\text { SES, Venovo }(16 \times 90 \\
14 \times 60,10 \times 40)\end{array}$ & $\begin{array}{l}\text { Symptom improvement, died } \\
2 \text { months later. }\end{array}$ \\
\hline $\begin{array}{l}\text { Maleux et al. } \\
\text { [10], } 2016\end{array}$ & 19 & 63.6 & $\begin{array}{r}\text { Malignancies }^{\mathrm{a}} \text { and } \\
\text { unknown causes }\end{array}$ & IFV or IVC & $\begin{array}{l}\text { SES, Wallstent, } \\
\text { Zilver, Bard (12, 14, } \\
20 \text { diameters) }\end{array}$ & $\begin{array}{l}\text { Symptom improvement in } 18 \\
\text { patients during postoperative } \\
\text { period, } 17 \text { patients died after } \\
24 \text { months. }\end{array}$ \\
\hline $\begin{array}{l}\text { O'Sullivan et al. } \\
\text { [2], } 2015\end{array}$ & 62 & $60.4 \pm 15.4$ & $\begin{array}{l}\text { Metastatic pelvic } \\
\text { disease }^{b}\end{array}$ & IFV and/or IVC & $\begin{array}{l}\text { SES, Wallstent, Zilver } \\
\text { Vena, Bard Luminexx, } \\
\text { sinus-Venous, Cordis } \\
\text { Smart (12-18 } \\
\text { diameter) }\end{array}$ & $\begin{array}{l}\text { Patients experienced better quality } \\
\text { of life and decreased LES; } \\
60 \text { patients died due to } \\
\text { underlying malignancies. }\end{array}$ \\
\hline $\begin{array}{l}\text { O'Sullivan et al. } \\
\text { [6], } 2013\end{array}$ & $20^{c}$ & $59 \pm 17$ & $\begin{array}{l}\text { Malignancy and } \\
\text { pelvic mass }^{\mathrm{d}}\end{array}$ & $\begin{array}{l}\text { LCIV, RCIV, } \\
\text { RCFV, LCFV, } \\
\text { LEIV, and REIV }\end{array}$ & $\begin{array}{l}\text { SES, Zilver Vena } \\
\quad(14-16 \times 60-100-140)\end{array}$ & $\begin{array}{l}3 \text { patients experienced early stent } \\
\text { thrombosis, improvement of LES } \\
\text { was observed in other patients. }\end{array}$ \\
\hline $\begin{array}{l}\text { Hama et al. } \\
{[5], 2005}\end{array}$ & 1 & 70 & $\begin{array}{l}\text { Right ureteral } \\
\text { carcinoma }\end{array}$ & $\begin{array}{l}\text { Bilateral iliac } \\
\text { veins and IVC }\end{array}$ & $\begin{array}{l}\text { SES, Wallstent } \\
(12 \times 90,10 \times 40 \text { and } \\
8 \times 70)+ \text { balloon- } \\
\text { expandable stents, } \\
\text { Palmaz Genesis } \\
(8 \times 30)\end{array}$ & $\begin{array}{l}\text { The stent remained patent after } \\
5 \text { months of follow-up. }\end{array}$ \\
\hline $\begin{array}{r}\text { Takai et al. } \\
\text { [8], } 2000\end{array}$ & 1 & 66 & Endometrial cancer & REIV & $\begin{array}{l}\text { SES, Memotherm, } \\
\text { Bard }(10 \times 70)\end{array}$ & $\begin{array}{l}\text { Symptom improvement for } \\
10 \text { months until the patient died. }\end{array}$ \\
\hline $\begin{array}{l}\text { Carlson et al. } \\
\text { [1], } 1995\end{array}$ & 10 & 56 & $\begin{array}{l}\text { Gynecologic } \\
\text { malignancies }^{\mathrm{e}}\end{array}$ & $\begin{array}{l}\text { LCIV, RCIV, } \\
\text { RCFV, LEIV, } \\
\text { and REIV }\end{array}$ & $\begin{array}{l}\text { SES, Gianturco and } \\
\text { Wallstent (15-20 } \\
\text { diameter) }\end{array}$ & $\begin{array}{l}\text { The patency of stents was 100\% } \\
\text { beyond } 6 \text { months of follow-up. } \\
\text { LES was improved. Two patients } \\
\text { died due to malignancy. }\end{array}$ \\
\hline $\begin{array}{l}\text { Antonucci et al. } \\
\text { [13], } 1992\end{array}$ & 3 & - & $\begin{array}{l}\text { Metastasis of cervical } \\
\text { cancer and ovarian } \\
\text { carcinoma }\end{array}$ & LCIV and IVC & $\begin{array}{l}\text { SES, Wallstent } \\
\begin{array}{l}(10-14 \times 50-150,25 \\
\text { diameter for IVC) }\end{array}\end{array}$ & $\begin{array}{l}\text { Patent stents at 6-9-month } \\
\text { follow-up. }\end{array}$ \\
\hline
\end{tabular}

Values are presented as mean \pm standard deviation.

REIV, right external iliac vein; SES, self-expandable stent; RCIV, right common iliac vein; RCFV, right common femoral vein; IFV, iliofemoral vein; IVC, inferior vena cava; LES, lower extremity swelling; LCIV, left common iliac vein; LCFV, left common femoral vein; LEIV, left external iliac vein.

aPatients' initial cancer: transitional cell carcinoma (TCC) of urethra, prostate cancer, TCC of bladder, adenocarcinoma of rectum, penile carcinoma, soft tissue sarcoma; ${ }^{b}$ Types of cancer affecting the patients: ovarian, breast, prostate, pancreatic, cervical, colon, lung, bladder, endometrial, lymphoma, penile, testicular, groin, liver, rhabdomyosarcoma, renal, gastric, mesothelioma, melanoma, retroperitoneal liposarcoma, and unknown causes; 'Ten patients with active malignancies; ${ }^{\mathrm{M}}$ Malignancies included bladder, prostate, ovarian, cervical, TCC, endometrial, retroperitoneal, and breast cancers; ${ }^{e}$ Vulvar, cervical, ovarian, uterine, and vaginal cancers.

and retroperitoneal cancers, can cause venous obstruction. The presenting symptoms were related to the location and severity of the mass. Tadayon et al. [11] reported a patient with papillary urothelial carcinoma of the bladder that recurred and extended to the right EIV. The patient was treated using a $12 \times 80-\mathrm{mm}$ venous stent. The procedure was successful, with an uneventful follow-up. Similarly,
O'Sullivan et al. [6] reported a series of nine patients with iliofemoral venous obstruction of the lower extremity resulting from malignant extrinsic compression. lliofemoral venous stenting was performed to re-establish the venous flow, and the patency rate was 85\%. In another report by O'Sullivan et al. [2], 62 patients with the metastatic pelvic disease and leg swelling were treated by venous stenting in 
the IVC and/or iliofemoral veins. They reported considerable alleviation of symptoms, patency in all patients, and improved quality of life.

Venous stenting for diffuse iliac vein stenosis and occlusion should be performed for the entire iliofemoral territory from the proximal CIV to the CFV. Skipping the normalappearing segments is not recommended because it could result in recurrences. The stents should be extended to the IVC at the proximal site, and they should reach the CFV in the distal site. Crossing the inguinal ligament does not involve a substantial risk in venous stenting, unlike the arterial system [14]. In addition, we performed stenting in all stenotic and occluded territories from the CIV to the CFV with extension to the IVC and infra-inguinal region. To prevent the potential risk of recurrence, all stenotic and occluded segments should be stented because angioplasty alone is prone to thrombosis, restenosis, and occlusion.

Venous stenting should be performed under intravascular ultrasound (IVUS) guidance. IVUS can detect venous lesions that are missed by venography. In addition, venography involves substantial risk of underestimating stenosis compared to IVUS [15]. Unfortunately, we did not perform IVUS at our center. We relied on venography in multiplane views, which is more effective than depending only on the $\mathrm{AP}$ view. The recommended standard stent sizes are 16 to $12 \mathrm{~mm}$ from the proximal to distal iliofemoral veins [14]. We used stents with diameters of 14 to $10 \mathrm{~mm}$ to prevent probable rupture in fibrotic veins.

In conclusion, venous stenting is a feasible and effective procedure to alleviate venous insufficiency of the lower extremities in patients with iliac vein compression due to pelvic malignancies. This method is particularly noteworthy in patients with unresectable pelvic masses and poor survival because venous stenting can potentially alleviate the symptoms for a considerable time. Despite the limited sur- vival period, devastating venous symptoms should not be neglected because active stenting can improve the quality of life of patients.

\section{ACKNOWLEDGEMENTS}

The authors would like to thank Dr. Annis Shahnaee for her kind assistance during the preparation of this article.

\section{CONFLICTS OF INTEREST}

The authors have nothing to disclose.

\section{ORCID}

Sina Zarrintan, https://orcid.org/0000-0002-3968-0221

Negin Yavari, https://orcid.org/0000-0002-9914-2935

Niki Tadayon, https://orcid.org/0000-0001-9431-4411

Fuad Majidi, https://orcid.org/0000-0001-8191-0601

Seyed Masoud Hosseini,

https://orcid.org/0000-0001-7960-4357

Hamidreza Haghighatkhah,

https://orcid.org/0000-0001-5411-0609

Ehsan Parvas, https://orcid.org/0000-0002-2562-5862

Seyed Mohammad Reza Kalantar-Motamedi,

https://orcid.org/0000-0001-7671-4382

\section{AUTHOR CONTRIBUTIONS}

Concept and design: SZ, NT, SMRKM. Analysis and interpretation: SZ, NT, FM, SMH. Data Collection: NY, FM, SMH, EP. Writing the article: SZ, NY. Critical revision of the article: SZ, NT, HH. Final approval of the article: SZ, NY, NT, FM, SMH, HH, EP, SMRKM. Statistical analysis: None. Obtained funding: None. Overall responsibility: NT, SMRKM.

\section{REFERENCES}

1) Carlson JW, Nazarian GK, Hartenbach

E, Carter JR, Dusenbery KE, Fowler $\mathrm{JM}$, et al. Management of pelvic venous stenosis with intravascular stainless steel stents. Gynecol Oncol 1995;56:362-369.

2) O'Sullivan GJ, Waldron D, Mannion E, Keane M, Donnellan PP. Thrombolysis and iliofemoral vein stent placement in cancer patients with lower extremity swelling attributed to lymphedema.
J Vasc Interv Radiol 2015;26:39-45.

3) Wasserburger J, Haponyuk A, Modhia UM, Langsfeld M, Paterson AJ, Rana MA. Lumbosacral exostosis as a rare cause of iliac vein compression and significant limb swelling. J Vasc Surg Cases Innov Tech 2019;5:529-531.

4) Ahsan I, Qureshi BG, Ghani AR, Malik F, Arif $\mathrm{Z}$. An extensive unprovoked left lower extremity deep vein thrombosis secondary to an anatomical anomaly: a case of May-Thurner syndrome. Clin Pract 2017;7:938.

5) Hama Y, Kaji T, Hayakawa M, Kosuda S. Endovascular stent placement for malignant stenosis and occlusion of the bilateral iliac veins and inferior vena cava after failure of radiation therapy. Minim Invasive Ther Allied Technol 2005;14:372-375.

6) O'Sullivan GJ, Sheehan J, Lohan D, McCann-Brown JA. lliofemoral venous 
stenting extending into the femoral region: initial clinical experience with the purpose-designed Zilver Vena stent. J Cardiovasc Surg (Torino) 2013;54:255-261.

7) Delis KT, Bountouroglou D, Mansfield AO. Venous claudication in iliofemoral thrombosis: long-term effects on venous hemodynamics, clinical status, and quality of life. Ann Surg 2004;239:118-126.

8) Takai N, Miyazaki T, Yoshimatsu J, Miyakawa 1. Treatment with a metallic endovascular stent in a patient with iliac venous stenosis due to endometrial cancer. Arch Gynecol Obstet 2000;264:51-53.

9) Nazarian GK, Austin WR, Wegryn SA, Bjarnason H, Stackhouse DJ, Castañeda-Zúñiga WR, et al. Venous recanalization by metallic stents after failure of balloon angioplasty or surgery: four-year experience. Cardiovasc Intervent Radiol 1996;19:227-233.

10) Maleux G, Vertenten B, Laenen A, De Wever L, Heye S, Clement P, et al. Palliative endovascular treatment of cancer-related iliocaval obstructive disease: technical and clinical outcomes. Acta Radiol 2016;57:451-456.

11) Tadayon N, Zarrintan S, Hosseini SM, Kalantar-Motamedi SMR. Iliac vein stenting in a patient with lower extremity swelling resulting from diffuse pelvic mass: a case report. J Cardiovasc Thorac Res 2021;13:84-86.

12) Taslakian B, Koneru V, Sista AK. Endovascular iliac vein reconstruction through an obstructive pelvic nodal recurrence of urothelial carcinoma.
CVIR Endovasc 2018;1:16.

13) Antonucci F, Salomonowitz E, Stuckmann G, Stiefel M, Largiadèr J, Zollikofer CL. Placement of venous stents: clinical experience with a selfexpanding prosthesis. Radiology 1992;183:493-497.

14) Jayaraj A, Raju S. lliocaval venous obstruction: endovascular treatment. In: Sidawy AN, Perler BA, editors. Rutherford's vascular surgery and endovascular therapy. 9th ed. Philadelphia: Elsevier; 2019. p. 2117-2121.

15) Murphy EH, Johns B, Varney E, Raju S. Endovascular management of chronic total occlusions of the inferior vena cava and iliac veins. J Vasc Surg Venous Lymphat Disord 2017;5:47-59. 